Article

\title{
Opto-Electronic Nose Coupled to a Silicon Micro Pre-Concentrator Device for Selective Sensing of Flavored Waters
}

\author{
Sami Slimani, Etienne Bultel, Thomas Cubizolle, Cyril Herrier, Tristan Rousselle and \\ Thierry Livache * D
}

Aryballe Technologies, 38000 Grenoble, France; s.slimani@aryballe.com (S.S.); e.bultel@aryballe.com (E.B.); t.cubizolle@aryballe.com (T.C.); c.herrier@aryballe.com (C.H.); t.rousselle@aryballe.com (T.R.)

* Correspondence: t.livache@aryballe.com; Tel.: +33-428-706-900

Received: 16 June 2020; Accepted: 30 July 2020; Published: 31 July 2020

check for updates

\begin{abstract}
Headspace analysis of highly humid samples remains a challenge for artificial olfaction. Based on surface plasmon resonance imaging and bio-based sensors, the NeOse Pro olfactive analyzer yields multivariate data and enhances the statistical discrimination capacity of odor patterns. However, the presence of a high background signal, such as water vapor from aqueous samples, may deteriorate its discriminant ability. Recently, miniaturized pre-concentrators packed with hydrophobic adsorbent have been developed to improve the detection limit of gas analysis methods and to enhance their selectivity by reducing the water's background signal. This work presents, for the first time, the coupling of a miniaturized silicon micro pre-concentration unit $(\mu \mathrm{PC})$ to a bio-based opto-electronic nose (NeOse Pro). The results showed that the coupling of a silicon $\mu$ PC with the NeOse Pro led to an improvement in the detection limit of n-nonane by at least a factor of 125 . Additionally, principal component analysis (PCA) of eight different flavored waters showed an enhanced discrimination ability of the coupled set-up in highly humid conditions.
\end{abstract}

Keywords: flavored water analysis; electronic nose; silicon micro pre-concentrator; background signal removing

\section{Introduction}

Designed to mimic the human olfactory sense, electronic noses are promising tools for the fast, reliable, and objective sensory evaluation of volatile aromas. Based on different sensor technologies, they offer an alternative approach to the use of human sensory panels and standard gas analytical techniques, which are bulky, expensive, and require expertise and maintenance e.g. Gas Chromatography coupled with Mass Spectrosopy (GC-MS), Selected Ion Flow Tube Mass Spectrometry (SIFT-MS) [1]. Since e-noses have reduced size, offer connectivity, and do not require a consumable carrier gas, they open doors to various applications in air quality, agriculture, cosmetics and fragrances, health, and public security [2-5]. Food applications are a suitable field for electronic noses, as flavors and aromas are predominant characteristics. Therefore, artificial olfaction techniques have the potential to become benchmark technologies in the food industry for food safety, quality control, food design, and manufacturing [6-11]. However, despite their intrinsic qualities, e-noses still suffer from limitations that keep their usage on a R\&D level. Among these limitations, real challenges still persist, such as poor detection limits, generally around the ppm level, the poor reproducibility of results since responses are influenced by environmental conditions, and sensitivity to water vapor, which is a major drawback for selectivity performance in analyzing humid samples [12-16]. Over the last few years, the development of new sensors to overcome these limitations have included sensors 
with hydrophobic characteristics [17] and new materials with promising sensing capabilities [18,19]. Algorithmic solutions have been proposed (e.g., humidity compensation and drift corrections) for better analytical performances of electronic noses and analytical gas sensors [20-24]. Original signal treatment, based on the exploitation of Volatile Organic Compounds (VOC) sensors and metal oxide semiconductor (MOS) interaction patterns, has also been described for a better sensibility and selectivity $[25,26]$. Another way to improve electronic nose capabilities consists of the use of adsorption/thermo-desorption (ATD) methods, as they offer the advantages of lowering detection limits and overcoming matrix interferences [27-30]. Among the examined solutions, the use of ATD seems to be particularly promising for the analysis of humid food samples and aqueous and alcoholic beverages [31-33]. Indeed, this sample preparation is a well-known approach to enhance the sensitivity and selectivity of an analytical method. The concentration of VOCs from a large volume of headspace (HS) by adsorption on a solid sorbent, followed by thermal desorption in a small volume of gas, allows improvement in the limit of detection (LOD) and limits humidity interference by using a hydrophobic sorbent (e.g., Tenax TA) [34]. Traditionally, a pre-concentrator system consists of a glass or metal tube packed with powder adsorbent and a large oven (often larger than the sensor itself), which requires high power consumption to heat up quickly. In the past ten years, micro pre-concentrators $(\mu \mathrm{PC})$ were developed for size and cost reductions, to reduce the form factor, power consumption, and time between measurements by optimizing the cool-down process [35-39]. Recently, the CEA-LETI laboratory (Grenoble, France) has developed a silicon $\mu \mathrm{PC}$ with an integrated heating function $[40,41]$. Filled with Tenax TA, this $\mu$ PC is associated with the NeOse Pro opto-electronic nose developed by Aryballe Technologies [42,43]. The association of an ATD unit with an e-nose has already been described, however, the very specific feature of the NeOse Pro opens new opportunities as its unique sensory element made of 68 oligopeptides confers a powerful discrimination capacity, including odorant isomers and optical enantiomers [44].

This paper presents the performances of this association through LOD reduction for nonane sensing as a model and the gain of selectivity when applied to beverages such as flavored waters, with typical samples exhibiting a very high background noise.

\section{Materials and Methods}

\subsection{Opto-Electronic Nose}

The NeOse Pro v2 device is an opto-electronic nose developed by Aryballe Technologies. Based on Surface Plasmon Resonance imaging (SPRi), the sensing part of the device consists of an oligopeptide array constructed on the surface of a gold film [42,43]. The resulting interactions with the VOCs (electrostatic, hydrogen, and/or Van-der-Waals bonds) are simultaneously tracked for all peptides as an increase in reflectivity. Generated signals are processed by the NeOse Pro app (v1.7.0) to obtain a specific olfactive signature. The fluidic part of the device, which ensures the exposition of the peptides to the VOCs, is composed of a pump $(60 \mathrm{~mL} / \mathrm{min}$ flowrate in standard method) and PTFE tubing ( $1 \mathrm{~mm}$ inner diameter). Additionally, the device integrates a hygrometer (Honeywell HIH6120) for humidity measurements of the sensed gas in its fluidic line.

In the direct measurement method, a typical analysis is carried out in a dozen seconds and is the result of sensing ambient air (as a baseline) and the volatile molecules originating from the headspace's sample to be analyzed. The detection limit of the NeOse Pro device ranges from tens of ppbv to hundreds of ppmv, depending on the nature of the molecule and its affinity to the oligopeptides.

\subsection{Silicon Micro Pre-Concentrator and Coupling to NeOse Pro Device}

The silicon micro pre-concentrator $(\mu \mathrm{PC})$ developed by CEA-LETI $[40,41]$ is designed as a miniature classical thermal desorption device. The chip size is $8 \times 21 \mathrm{~mm}$. The central cavity was etched in silicon on the front side by deep reactive ion etching. The cavity was filled with around $7 \mathrm{mg}$ of Tenax TA adsorbent (mesh 80-100) and can be seen on Figure 1. The chip was then sealed on top by Pyrex 
glass by anodic bonding. The backside was covered by a thermo-resistive Ti/Pt film heater (Figure 1), allowing quick heating to $200{ }^{\circ} \mathrm{C}$ for the thermal desorption of the trapped VOCs. An external thermal probe stuck on the surface (PT100, RS Pro) was used for thermal control. The fluidic connections were made of stainless steel tubing (500 $\mu$ m i.d.; $790 \mu$ m e.d.).

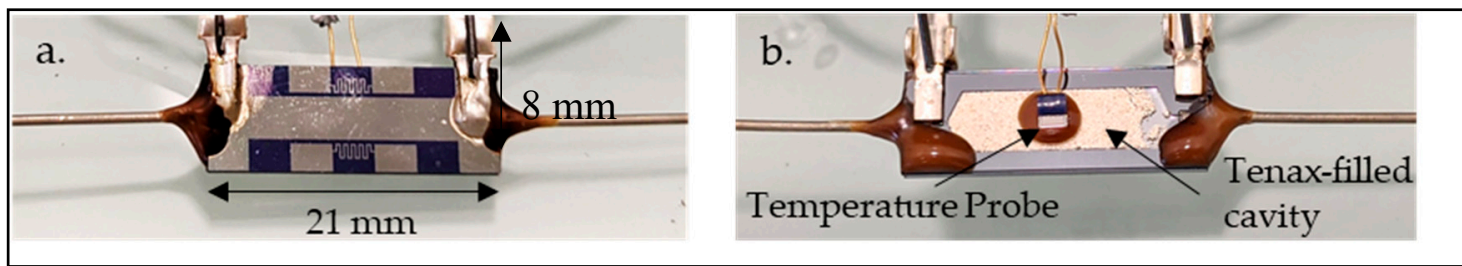

Figure 1. Illustration of $\mu$-concentration system, (a) the Ti/Pt heating film and temperature probe deposit, (b) the opposite side cavity filled with Tenax TA (80-100 mesh).

The $\mu$ PC was connected to the sample via a $1 \mathrm{~mm}$ i.d. PTFE pipe, which ended with a stainless steel 18-gauge needle and to the NeOse Pro device via a three-way valve (Figure 2). The valve allowed the transition between sample concentration, baseline sensing (room air), and the sensing of desorbed VOCs.

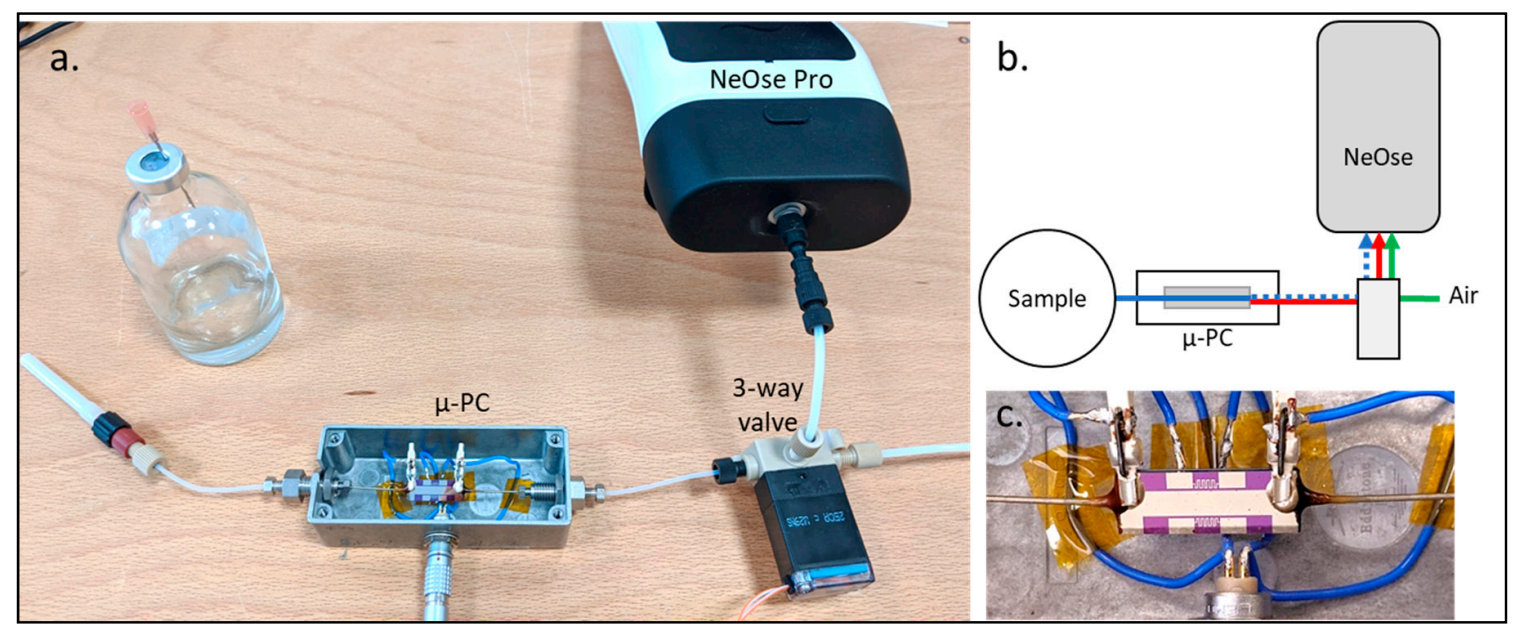

Figure 2. NeOse Pro and $\mu$-preconcentration system coupling. (a) Experimental setup, with the sample vial. (b) Schematic view of the NeOse Pro/micro pre-concentrator ( $\mu \mathrm{PC}$ ) system where the blue line represents the sample flow path: the full blue line represents the accumulation of analyte on Tenax TA, while the dotted line represents the non-adsorbed compounds during the concentration step (e.g., water), the red line represents the thermal desorption from the $\mu \mathrm{PC}$, and the green line represents the reference air input. (c) View of the preconcentration chip on the metalized side.

As for the direct analysis method, the measurement of desorbed VOCs is the difference between the baseline signals and the one from the sensed desorbed VOCs.

\subsection{Detection Limit Assays of NeOse Pro Direct and Coupled to the Silicon Micro Pre-Concentrator}

Nonane (Sigma Aldrich, St Quentin Fallavier, France) was used, as a VOC model, to characterize the signal amplification capacity of the silicon $\mu$ PC when coupled with the NeOse Pro sensor. To prevent any matrix effect, dilutions of n-nonane were carried out in $80 \mathrm{~mL}$ glass tubes with PTFE septum screw caps, using low volatile mineral oil. Nonane samples from $0.01 \%(\mathrm{~m} / \mathrm{m})$ to pure nonane were analyzed either by direct measurement or coupled with $\mu$ PC system. Levels of dilutions of the samples and corresponding headspace concentration can be found in Table 1. 
Table 1. Liquid dilution of n-nonane in mineral oil and corresponding headspace concentration.

\begin{tabular}{ccccccccccc}
\hline Nonane/Oil (m/m) \% & 0 & 0.01 & 0.05 & 0.1 & 0.5 & 1 & 5 & 10 & 50 & 100 \\
\hline [TVOC] (ppmv) & 1.3 & 3.6 & 9 & 14 & 62 & 106 & 462 & 646 & 780 & 805 \\
\hline
\end{tabular}

The ATD analysis occurred in different steps. The HS sample was firstly injected into the $\mu$-concentrator at $80 \mathrm{~mL} / \mathrm{min}$ over $1 \mathrm{~min}$ at room temperature and a 1-min purge was performed to clean dead volumes. A baseline reference value was then recorded via the valve tube sampling ambient air while the $\mu \mathrm{PC}$ system was heated to $200^{\circ} \mathrm{C}\left(12{ }^{\circ} \mathrm{C} / \mathrm{s}\right.$ heating speed $)$. When the targeted temperature was reached, the three-way valve switched the gas flow from the ambient air to the $\mu \mathrm{PC}$, carrying the desorbed analytes to the NeOse Pro. On the resulting SPRi sensorgram, a thermo-desorption peak could be observed for each curve representing the \%Reflectivity evolution of an oligopeptide.

\subsection{Signal Interpretation of n-Nonane Assays}

To define a significative signal, a threshold value was calculated using the signals gathered by the mineral oil solvent measurement and the three-sigma approach, leading to the determination of the limit of the significance threshold (threshold $=$ mean blank $+3 \sigma_{\text {blank }}$, with $\sigma_{\text {blank }}=$ blank standard deviation). The chosen criterion from the nonane measurements to be compared to this threshold was the Imax value, defined as the average intensity of all oligopeptides when the signals reached their maximum.

\subsection{Flavored Water Samples}

Eight flavored waters were purchased from a local supermarket (Grenoble, France) and stored at $(5 \pm 3)^{\circ} \mathrm{C}$ until their analysis. The sample list is available in Table 2.

Table 2. Headspace Volatile Odor Compounds (VOC) concentration for each flavored water sample.

\begin{tabular}{cccc}
\hline Sample Code & Flavored Water & Descriptive Flavor & PID (ppmv) \\
\hline Water & - & Non-flavored & $<0.001$ \\
\hline A & $\begin{array}{c}\text { Volvic Juicy Agrumade } \\
\text { Pamplemousse }\end{array}$ & Grapefruit & 111.0 \\
\hline B & $\begin{array}{c}\text { Volvic Juicy } \\
\text { Citronade }\end{array}$ & Lemonade & 17.0 \\
\hline $\mathrm{C}$ & $\begin{array}{c}\text { Volvic ZEST } \\
\text { Citron }\end{array}$ & White Peach & 10.5 \\
\hline $\mathrm{D}$ & $\begin{array}{c}\text { Volvic Thé Vert } \\
\text { Pêche Blanche }\end{array}$ & 11.0 \\
\hline $\mathrm{E}$ & $\begin{array}{c}\text { Volvic Juicy Bio } \\
\text { Fraise }\end{array}$ & Organic Strawberry & 7.0 \\
\hline $\mathrm{F}$ & $\begin{array}{c}\text { Volvic Juicy } \\
\text { Fraise }\end{array}$ & Strawberry & 66.5 \\
\hline $\mathrm{G}$ & $\begin{array}{c}\text { Volvic Juicy Bio } \\
\text { Pomme }\end{array}$ & Organic Apple & 17.0 \\
\hline $\mathrm{H}$ & $\begin{array}{l}\text { Volvic Infusion Rooibos } \\
\text { Mangue \& Fruits de la passion }\end{array}$ & Mango \& Passion fruit & \\
\hline
\end{tabular}

\subsection{NeOse Pro Direct Analysis of Flavored Waters}

NeOse direct analysis of flavored waters was carried out using an eight-way valve (Heptavalve from Aryballe) coupled to the NeOse olfactive analyzer device (flow rate: $30 \mathrm{~mL} / \mathrm{min}$ ). This system, run by the NeOse App (v1.0.7), allowed automatic and periodic measurements of the samples. 
Before analysis, $5 \mathrm{~mL}$ of each flavored water were added into $50 \mathrm{~mL}$ headspace bottles and immediately sealed using crimp caps (silicone/PTFE septum). To allow headspace formation, bottles were stored for $2 \mathrm{~h}$ in the dark at room temperature. Prepared samples were connected to the Heptavalve by tubing made of $1 \mathrm{~mm}$ i.d. PTFE. A vent made by a Sterican $18 \mathrm{G}$ needle was used during the analysis to allow a pressure equilibrium in the headspace bottles. During the analysis, sample and headspace homogenization were performed using a magnetic stirrer. For each sample, three measurements were performed using ambient air as a baseline.

\subsection{NeOse Pro/ATD Analysis of Flavored Waters}

Ten milliliters of each flavored water and a non-flavored water sample (control) were added into $100 \mathrm{~mL}$ headspace bottles which were immediately sealed using crimp caps with PTFE septa. To allow headspace formation, bottles were stored for $2 \mathrm{~h}$ in the dark at room temperature. For each sample, three bottles were prepared for triplicate analysis.

During the concentration step $(30 \mathrm{~mL} / \mathrm{min}$ flow rate, $180 \mathrm{~s}$, room temperature), a vent, made by a Sterican $18 \mathrm{G}$ needle, was used to allow the pressure equilibrium of the headspace bottles. Before the thermo-desorption measurement, samples were disconnected, and the $\mu$-PC purged with ambient air. Desorbed VOCs were measured while Tenax TA was heated at $200{ }^{\circ} \mathrm{C}$ (heating slope $20{ }^{\circ} \mathrm{C} / \mathrm{s}$, $10 \mathrm{~mL} / \mathrm{min}$ flow rate, $30 \mathrm{~s}$ ).

\subsection{Data Processing for Multivariate Analysis of Water Samples}

As the resulting sensorgram differs from the two compared measurement modes, the signal processing of direct measurement records was based on the plateau part of the signal (signals gathered from $20 \mathrm{~s}$ to $30 \mathrm{~s}$ of measurement). For ATD measurement records, the part of the signal used for signal processing was based on the reflectivity variation observed within 40 to $50 \mathrm{~s}$. To ease data interpretation, multivariate datasets were compared using principal component analysis (PCA) after zeroing using the baseline signal and L2 normalization.

To objectively delimit sample clustering, the statistical dispersion of the replicates was represented on the PCA plot. After calculating the centroid of each population, solid and dotted line circles, both centered on the centroid, respectively represent the average PCA distance of the replicates to their centroid and the average PCA distance plus $2 \sigma$ dispersion, where $95 \%$ of the population would be found.

\subsection{Total VOC Measurement}

To get an indication of the gas phase concentration of the nonane and the flavored water assay, the total VOC concentration of headspaces was measured with a photo-ionization detector (PID Mini RAE 3000-RAE Systems by Honeywell, Charlotte, NC, USA). Sample measurements were done in the same conditions as the NeOse direct and ATD sensing.

As the calibration of the PID was done with 10 ppmv isobutylene, the given values of the measurements were expressed in ppmv equivalent to isobutylene for the flavored samples and in corrected ppmv for nonane measurements (correction factor given by the manufacturer).

\section{Results and Discussion}

In order to characterize the analytical performances of the $\mu \mathrm{PC} / \mathrm{NeOse}$ Pro coupling, detection limit and discrimination capacity assays were performed using direct and ATD measurement methods.

\subsection{NeOse Pro Direct and Thermo-Desorbed Sensing of Nonane Dilutions}

The detection limits of the direct and ATD measurement methods were determined by using different dilutions of n-nonane in low volatile mineral oil and by comparing the intensity of the gathered signals to a threshold calculated using the $3 \sigma$ approach. 
The gas concentration of nonane in the HS of each dilution was measured using a PID. Concentrations were found to range from $3.6 \mathrm{ppmv}$ for the highest dilution rate $(0.01 \% \mathrm{~m} / \mathrm{m})$ to $805 \mathrm{ppmv}$ for the non-diluted nonane sample. The PID measurement of the mineral oil solvent also showed some VOCs in the headspace at a concentration of 1.3 ppmv, while VOC concentration in lab air was under the detection limit ( $<1 \mathrm{ppbv})$ (Table 1$)$. As for the lowest dilution rates, gas concentrations of nonane were not linearly proportional to their liquid concentrations, so the gas concentration values were used for the LOD comparisons.

Using the two methods, the recorded signals showed two different and typical patterns (Figure 3). With direct measurement, the NeOse sensing of a sample generated an increase in reflectivity until it reached a maximum value (plateau). Then, the signal remained stable as the sensing of the sample continued (Figure 3b,c). A decrease in reflectivity to the baseline level was reached within a few seconds when disconnecting the sample and flushing the biosensors with ambient air (data not shown). With the use of the $\mu \mathrm{PC}$, the signal generated an increase in reflectivity when the sorbent affinity for nonane decreased under the effect of heating. Then the reflectivity went back to the baseline level as all the trapped VOCs were released (Figure $3 \mathrm{~d}-\mathrm{f}$ ).

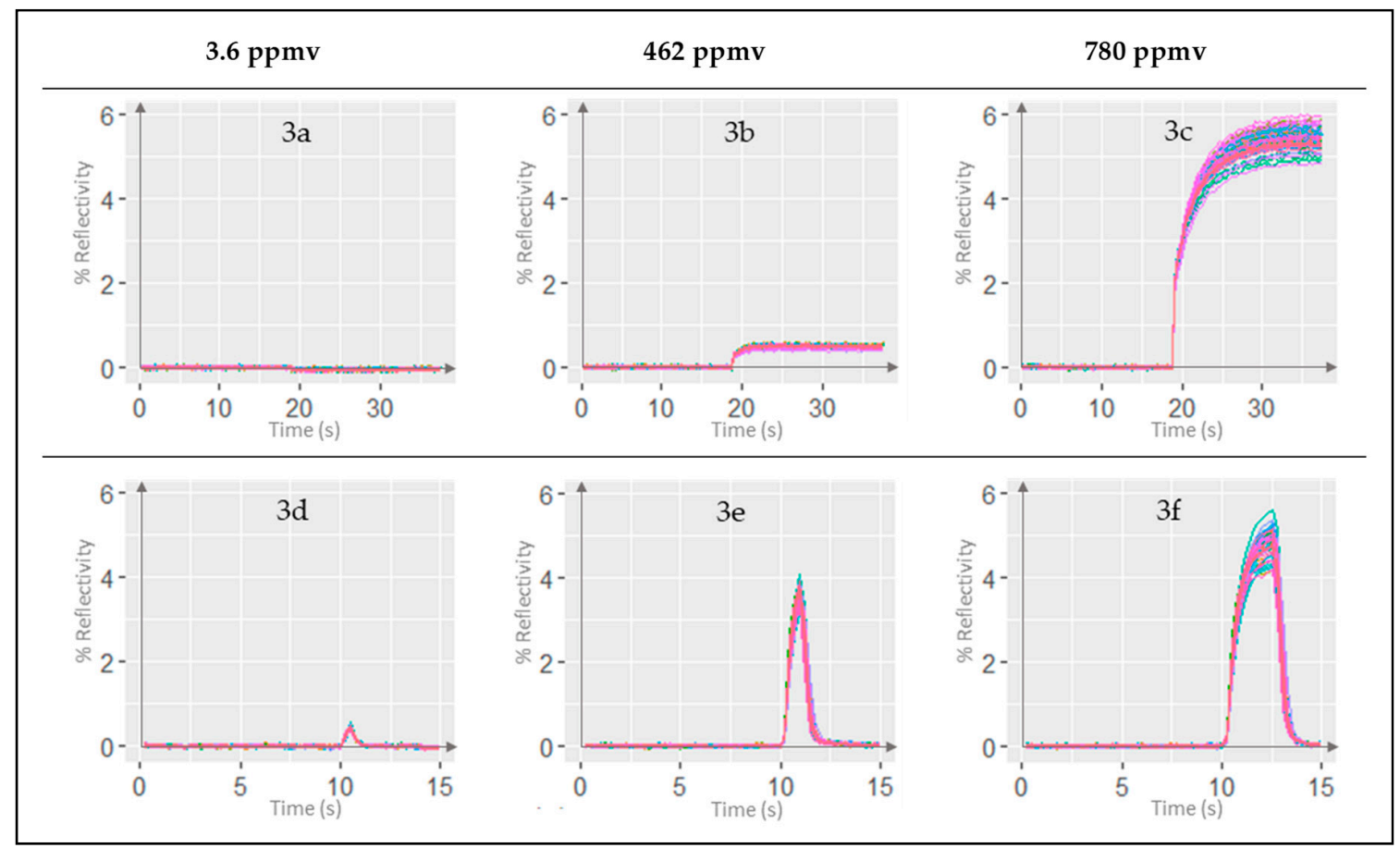

Figure 3. Sensorgram comparison of n-nonane headspace analysis with direct measurement (a-c) and with concentration technique (d-f) for three different gas concentrations: $3.6 \mathrm{ppmv}, 462 \mathrm{ppmv}$, and 780 ppmv of n-nonane. Direct measurement generates a steady signal to a plateau, while the concentration technique generates a desorption peak.

Due to this difference in sensorgram patterns and for comparison purposes, the I $\overline{m a x}$ value criterion was chosen. The direct measurement of mineral oil led to a calculated significance threshold of $0.1 \%$ reflectivity. Using the NeOse Pro/ATD approach, the calculated significance threshold was found to be $=0.4 \%$.

The significance threshold was found to be higher for the ATD measurement method than for the direct one. This result was due to the presence of volatile compounds in the mineral oil HS, which was not detected by direct sensing but did generate a signal using the silicon $\mu \mathrm{PC}$.

Hence, according to their respective thresholds and the Imax value calculated for each nonane dilution, signals recorded from samples with a nonane concentration under $5 \%(\mathrm{~m} / \mathrm{m})$ were not considered as significant signals in the direct measurement mode, whereas with the ATD setup, 
the highest dilution of nonane tested $(0.01 \% \mathrm{~m} / \mathrm{m})$ gave a significant signal. In the present experimental conditions, the detection limit of nonane was found to be around $462 \mathrm{ppmv}$ for NeOse Pro direct sensing and around 3.6 ppmv for the NeOse Pro ATD sensing (Figure 4).

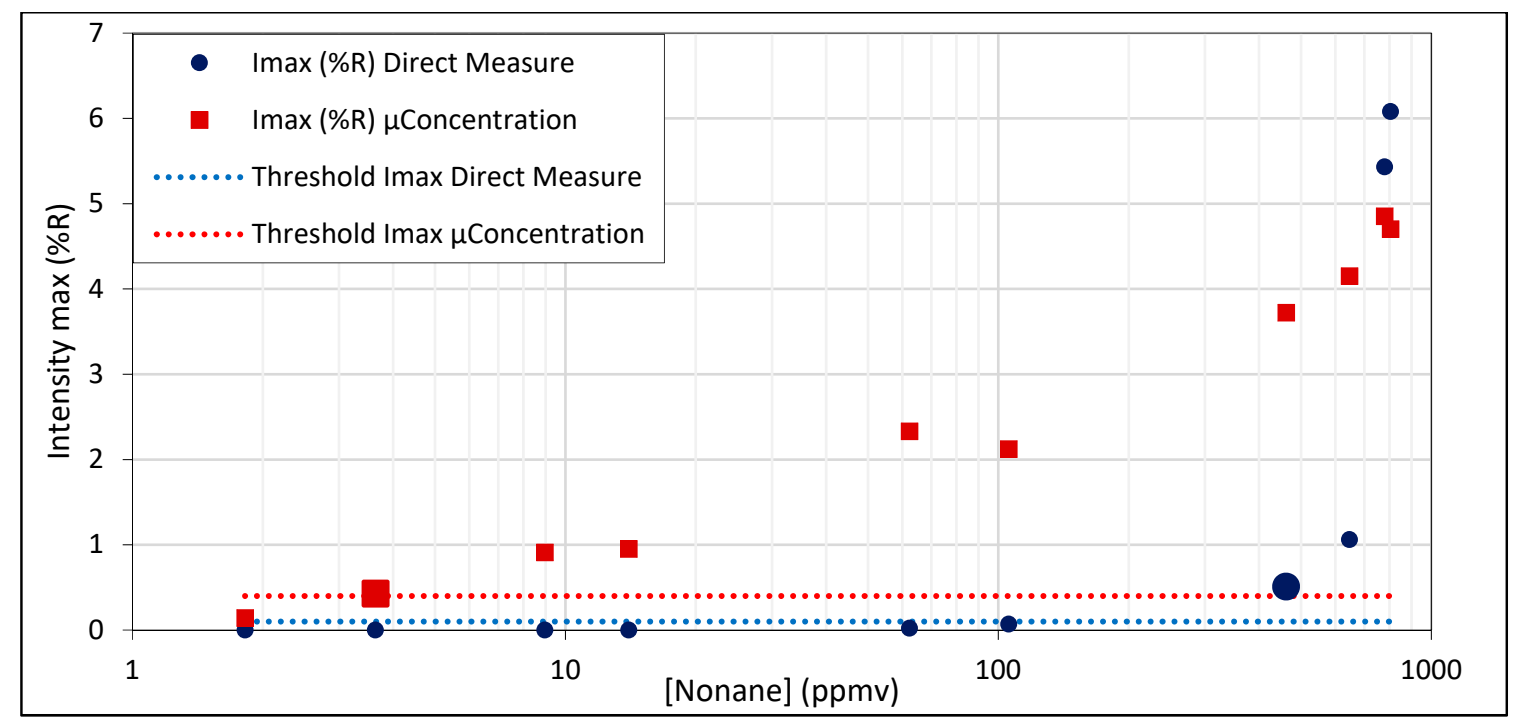

Figure 4. Detected max intensity vs. nonane gas concentration for both acquisition methods.

Hence, when coupling the NeOse Pro to the micro pre-concentrator device, the detection limit was found to be lowered 125 -fold. As $80 \mathrm{~mL}$ of headspace content were trapped and released in a volume of $1.3 \mathrm{~mL}$, it is worth noticing that the 125-fold LOD reduction was led by an HS concentration factor of 61-fold. Therefore, the LOD reduction factor could be optimized by concentrating a higher volume of HS, until reaching the Tenax TA breakthrough volume for n-nonane. Considering that NeOse Pro sensibility and Tenax affinity vary with the chemical nature of the analyzed VOC, the performance based on the nonane assay should be considered as a model rather than a generalized characteristic of the tested set-up. Despite these considerations, the results remain consistent with the ones described in similar studies. In 2015, Thomas C.M. et al. coupled a conducting polymer olfactory sensor with an enrichment desorption unit filled with Tenax TA for the detection of different VOCs and described the sensing performance enhancement, ranging from a dozen to a thousand times [29]. Additionally, the $\mu \mathrm{PC}$ has been characterized in a previous study, in which the authors concluded a concentration factor of a thousand times for toluene [40].

\subsection{Flavored Water Sensing}

Discrimination capacity in saturated humidity conditions was investigated using the silicon $\mu$ PC. To perform these tests, eight flavored waters and a non-flavored one were analyzed with the direct sensing and ATD methods.

\subsubsection{Total VOC Measurements}

PID measurements of the flavored waters showed two levels of VOC concentration: samples A and $\mathrm{G}$ with HS contents of several dozen ppmv and the other samples with concentrations around 10 ppmv. As PID measurement is not sensitive to humidity, the non-flavored water measurement was under the ppbv level (Table 2).

\subsubsection{NeOse Pro Direct and ATD Sensing of Flavored Water}

Despite the difference in VOC concentrations, direct sensing of the water samples showed equivalent signal intensities for all the waters, including the non-flavored one (Figure 5a-c). During these assays, the relative humidity levels of the samples were found to be equivalent and around 
$70 \%$, indicating a water concentration in the HS of around 16,000 ppmv. Those results showed that water vapor can interact with the NeOse Pro bio-based sensors. Hence, the signals gathered from the flavored waters were mostly related to the presence of water in their gas phase.

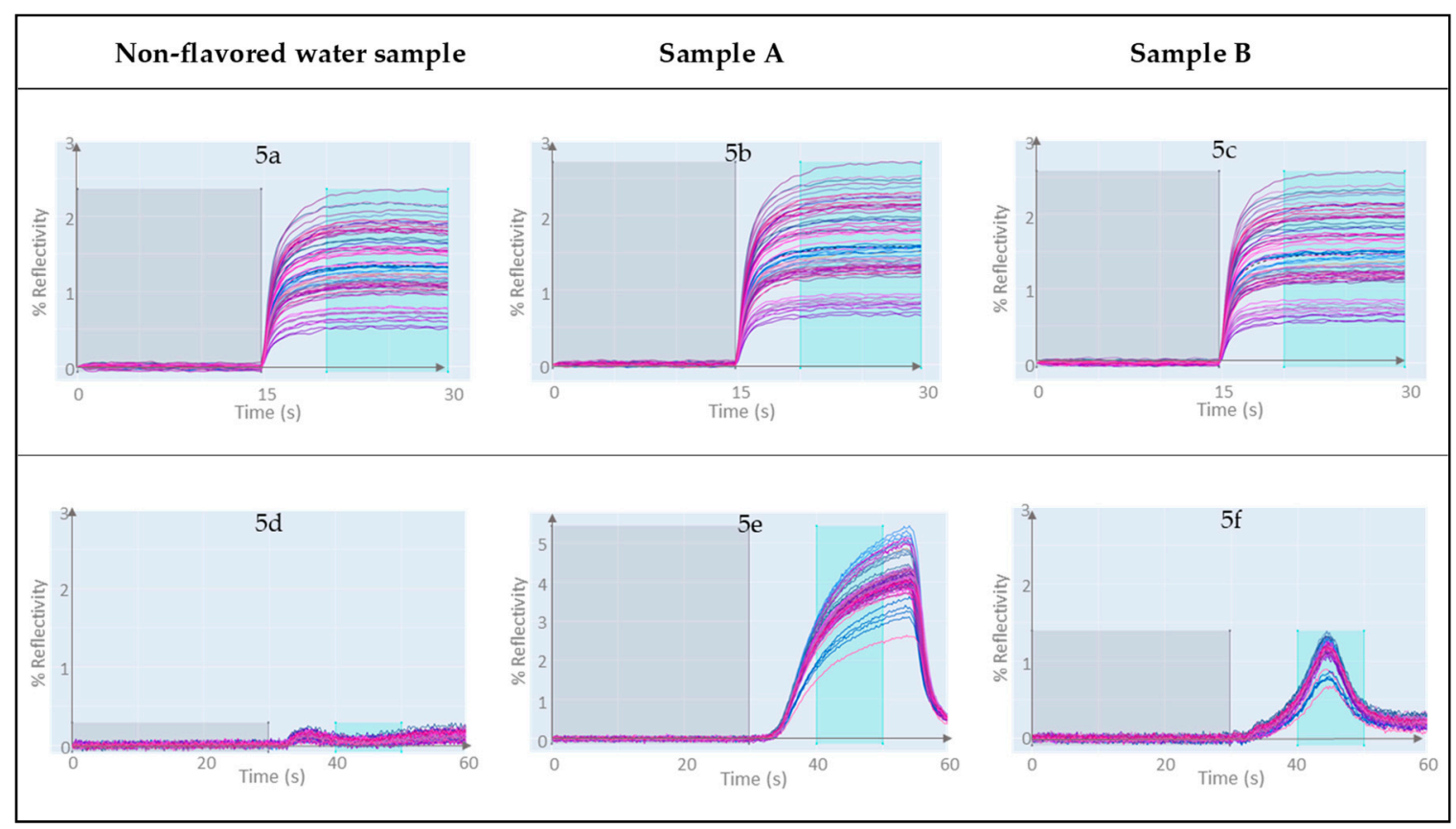

Figure 5. Examples of sensorgrams obtained from three water samples using direct measurement $(\mathbf{a}-\mathbf{c})$ and Adsorption Thermal Desorption (ATD) techniques $(\mathbf{d}-\mathbf{f})$. The gray window corresponds to the baseline signal and the blue one corresponds to the sample signal part used for data treatment.

As described for the nonane detection limit assays, the shapes of the signals obtained with the use of the $\mu \mathrm{PC}$ differ from the ones in the direct analysis. Figure $5 \mathrm{~d}-\mathrm{f}$ show examples of signals gathered from different water samples. When using the ATD sensing method, the first noteworthy point is the absence of a significant signal for the non-flavored water, while all the flavored ones led to a significant signal (according to the three-sigma approach). This finding is due to the very low affinity of the Tenax TA sorbent for small polar molecules, like water vapor. Therefore, the signals gathered for the flavored samples can be easily correlated to the presence in their HS of VOCs other than gaseous water.

To standardize the calculation of odor patterns, the plateau part of the signals was used for all the samples sensed with the direct method (signals recorded from 20 to $30 \mathrm{~s}$ ). For the ATD sensing method, pattern calculation was based on the signal variation recorded from 40 to $50 \mathrm{~s}$, as this period fits for all the tested samples (data not shown).

A deeper multivariate data analysis of the odor pattern datasets generated from these two measurement methods were performed using principal component analysis (PCA). PCA is a well-known analytical tool in the domain of sensor arrays, as it offers the advantages of visualizing in two dimensions multidimensional data and highlighting the relations between the analyzed samples [45]. However, despite those major advantages, the reading and interpretation of a PCA plot could be difficult to handle for a non-initiated user. Therefore, objective criteria are needed when it comes to differentiating closely related samples. In this work, we propose to ease the reading and the interpretation of the PCA representation by showing on the graphic probabilistic areas calculated from the replicates of each sample. Areas delimited by dotted circles denote the probability of $95 \%$ of sample occurrence (see Section 2.8). Therefore, sample clusters with non-overlapping certainty areas are considered as differentiated. Additionally, previously to any statistical analysis, the datasets were tested using the Shapiro-Wilk test with a $p$-value threshold of 0.05 and were found to follow the normal distribution. 
The PCA built with the direct sensing datasets (Figure 6), shows that samples A and G (Grapefruit and Organic Apple) could be well separated from the others. This finding contrasts with the observations made for the other samples. Indeed, as the certainty areas of samples E, F, and H (Strawberry, Organic Strawberry, and Mango \& Passion fruit) overlapped with the non-flavored water, they could not be differentiated. Samples B, C, and D (Lemonade, Lemon, and White Peach) also showed overlapping areas, but formed another distinct cluster. A dendrogram representation of the PCA distances can be seen in the supplementary file. As the first two components of the PCA explain $85 \%$ of the variance, we can conclude a non-differentiation of the samples in the direct measurement mode except for the samples A and G. Those two well-separated samples exhibited the highest VOC rates, while the other samples were found to be up to 10 times less concentrated (Table 2). Therefore, a clear link of these results with the VOC concentration is shown and might be explained by the competition on the surface sensor between the targeted VOCs and water molecules [11-15]. Indeed, it is not obvious to look for a compound present at a ppmv range in a headspace containing a saturated concentration of water vapor, i.e., 16,000 ppmv. This finding also shows that, in the direct sensing method, the differentiation of flavored waters seems to be possible when the ratio of targeted VOC/water VOC is around 1/100. However, the quantitative characteristic of the HS seems to not be enough to explain the discrimination capacity of flavored water. Indeed, the direct measurement samples B, C, and D could be differentiated from the non-flavored water, while they presented the same VOC concentration rate as samples $\mathrm{E}, \mathrm{F}$, and $\mathrm{H}$. Hence, a difference in the peptide sensor sensitivities to the nature of the VOCs might complete the $1 / 100$ ratio explanation.

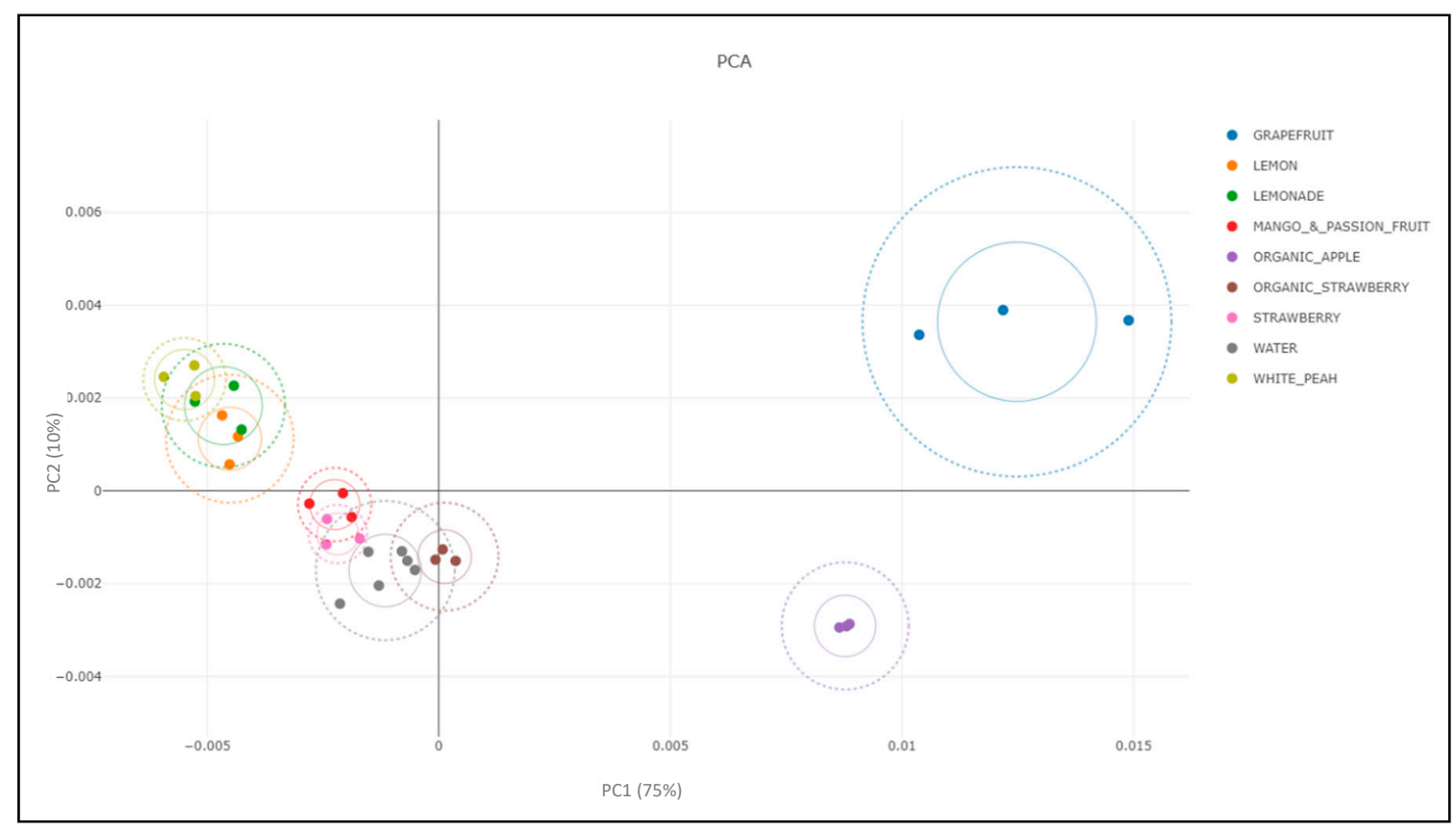

Figure 6. Principal component analysis plot based on the direct sensing of nine different waters. Dots represent replicates of sample measurements and dotted line circles represent the statistical dispersion calculated for each sample (color code for samples: blue = Grapefruit; orange $=$ Lemon; green = Lemonade; red = Mango \& Passion Fruit; purple = Organic Apple; brown = Organic Strawberry; pink $=$ Strawberry; yellow $=$ White Peach).

The principal component analysis 2D plot built with the ATD sensing datasets and totaling $94 \%$ of the variance shows clear discrimination of all the samples since none of the certainty areas overlap (Figure 7). A dendrogram representation of the PCA distances can be seen in the supplementary file. The discrimination performance of the NeOse Pro sensing, when coupled with the silicon $\mu$ PC, contrasts with the direct sensing method. The use of the hydrophobic Tenax TA sorbent allows for 
the removal of the common and abundant interferent water compounds, enhancing the discrimination ability of the NeOse Pro. This well-known characteristic of Tenax TA has been previously exploited to successfully differentiate eight liquors using semi-conductor gas sensors coupled with a Tenax concentration unit [46]. In addition, it is interesting to compare this discrimination performance with the results published in 2011 by Cole et al. In their study, they achieved complete discrimination between three aqueous samples (orange juice, water, and milk) by using a combined electronic tongue and nose system for both liquid and gas phase sensing. However, the authors concluded that the discrimination performance was mostly due to the electronic tongue, the electronic nose having shown a little contribution to the sample discrimination [33]. In our study, we have shown that the NeOse Pro device, when combined with a $\mu \mathrm{PC}$, could achieve the same discrimination performance for aqueous beverages by only focusing on HS analysis.

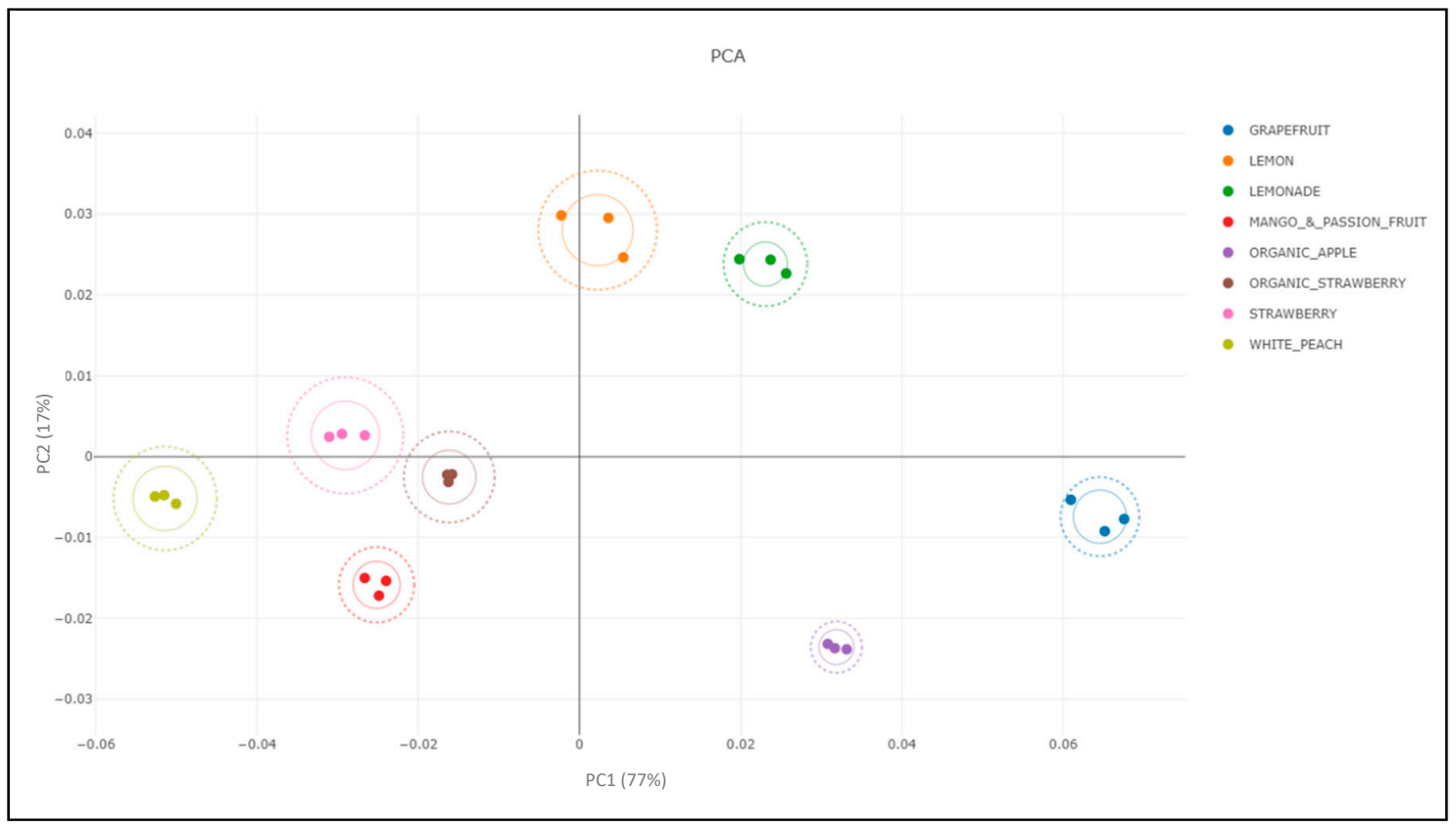

Figure 7. Principal component analysis plot based on the ATD sensing of eight flavored waters. Dots represent replicates of sample measurements and dotted line circles represent the statistical dispersion calculated for each sample (color code for samples: blue = Grapefruit; orange = Lemon; green = Lemonade; red = Mango \& Passion Fruit; purple = Organic Apple; brown = Organic Strawberry; pink $=$ Strawberry; yellow $=$ White Peach).

In addition to the gain of selectivity provided by the use of the $\mu \mathrm{PC}$, the mechanism of VOC concentration might also play a role in the differentiation ability for the flavored samples since it allowed us to lower the detection limit of the targeted VOCs.

Moreover, the ATD method managed to separate the two citrus samples, B and C, and the two strawberry ones, E and F. As their food label did not indicate their chemical compositions, it is difficult to conclude the reason for this separation, but as they are commercialized by the same manufacturer under different references, we can suppose that qualitative and/or quantitative differences exist in their compositions.

Among the reported solutions dealing with water interference removing, the use of hydrophobic sensors, such as modified polyaniline, seems to constitute a limited alternative, as its utilization is limited to headspace with no more than hundreds of ppmv of water, while aqueous samples exhibit thousands of ppmv [17]. Multiple algorithmic approaches have been described and seem to constitute a credible way for managing humidity interferences, as their use can improve the analytical performances of the gas sensors [21]. However, a calibration step is often needed and it has to be regularly updated because of sensor drift [20]. The use of ATD methods also seems to be very efficient 
for strong background removal since they were successfully applied in different application fields and particularly in the food analysis domain. Using a traditional $150 \mathrm{mg}$ Tenax TA tube, Muenchmeyer et al. were able to lower, by a factor 10, the detection limit of toluene in the presence of ethanol [34]. In this study, the authors also showed the usefulness of the ATD method for the analysis of alcoholic beverages. In another study, the authors managed to differentiate mushrooms of the same variety using a carbon graphite-based ATD method, which was not possible by direct measurement because of the presence of water and ethanol in the sample headspace [32]. However, since the qualitative and quantitative composition of the collected VOCs will be influenced by their affinity to the sorbent, the use of an ATD method can influence the measured flavor. In addition, the heating of the sorbent to high temperatures can impact the chemical nature of the VOCs, and consequently change their native interactions with the sensors [47]. Therefore, the choice of the method for dealing with water interferences for the analysis of highly humid gas samples must take into consideration its intrinsic advantages and limits.

\section{Conclusions}

The use of a silicon micro pre-concentrator allows for enhancement of the NeOse Pro detection limit and the selective sensing of a low level of flavor compounds in the presence of a high concentration of water vapor. Associated with the high power of chemical discrimination of the opto-electronic nose, this coupling opens up high-resolution analysis, dealing with aqueous media found in food and beverage applications. This approach can be further extended to the analysis of products containing a high concentration of polar solvents, such as ethanol, opening the field of the e-nose-based quality control of alcoholic beverages and perfumes.

Supplementary Materials: The following are available online at http://www.mdpi.com/2227-9040/8/3/60/s1, Figure S1: Dendrogram representation of PCA distances based on direct measurements of nine different waters. Figure S2: Dendrogram representation of PCA distances based on ATD measurements of eight flavored waters.

Author Contributions: Conceptualization, E.B. and C.H.; Formal analysis, S.S.; Funding acquisition, T.R.; Methodology, S.S.; Project administration, T.L.; Resources, T.C., C.H., and T.R.; Software, T.C.; Supervision, T.L.; Validation, T.L.; Writing-original draft, S.S. and E.B.; Writing-review and editing, C.H. and T.L. All authors have read and agreed to the published version of the manuscript.

Funding: This research was supported by the NEw Olfactory SEnsor applied to Fermentation Flavor \& Food $\left(\right.$ NEOSE F ${ }^{3}$ ) PIA3 project, France Agrimer, BPI France.

Acknowledgments: The authors would like to acknowledge Liz Facteau for her proofreading and Severine Vignoud (CEA, Leti) for the pictures of the micro pre-concentrator device.

Conflicts of Interest: All authors belong to Aryballe Technologies.

\section{References}

1. Wardencki, W.; Chmiel, T.; Dymerski, T. Gas chromatography-olfactometry (GC-O), electronic noses (e-noses) and electronic tongues (e-tongues) for in vivo food flavour measurement. In Instrumental Assessment of Food Sensory Quality; Elsevier: Amsterdam, The Netherlands, 2013; pp. 195-229.

2. Wilson, A.; Baietto, M. Applications and Advances in Electronic-Nose Technologies. Sensors 2009, 9, 5099-5148. [CrossRef] [PubMed]

3. Karakaya, D.; Ulucan, O.; Turkan, M. Electronic Nose and Its Applications: A Survey. Int. J. Autom. Comput. 2020, 17, 179-209. [CrossRef]

4. Rocco, G. Every breath you take: The value of the electronic nose (e-nose) technology in the early detection of lung cancer. J. Thorac. Cardiovasc. Surg. 2018, 155, 2622-2625. [CrossRef] [PubMed]

5. Spinelle, L.; Gerboles, M.; Kok, G.; Persijn, S.; Sauerwald, T. Review of Portable and Low-Cost Sensors for the Ambient Air Monitoring of Benzene and Other Volatile Organic Compounds. Sensors 2017, 17, 1520. [CrossRef]

6. Shi, H.; Zhang, M.; Adhikari, B. Advances of electronic nose and its application in fresh foods: A review. Crit. Rev. Food Sci. Nutr. 2018, 58, 2700-2710. [CrossRef] 
7. Wilson, A.; Oberle, C.; Oberle, D. Detection of Off-Flavor in Catfish Using a Conducting Polymer Electronic-Nose Technology. Sensors 2013, 13, 15968-15984. [CrossRef]

8. Loutfi, A.; Coradeschi, S.; Mani, G.K.; Shankar, P.; Rayappan, J.B.B. Electronic noses for food quality: A review. J. Food Eng. 2015, 144, 103-111. [CrossRef]

9. Wojnowski, W.; Majchrzak, T.; Dymerski, T.; Gębicki, J.; Namieśnik, J. Electronic noses: Powerful tools in meat quality assessment. Meat Sci. 2017, 131, 119-131. [CrossRef]

10. Karlshøj, K.; Nielsen, P.V.; Larsen, T.O. Prediction of Penicillium expansum Spoilage and Patulin Concentration in Apples Used for Apple Juice Production by Electronic Nose Analysis. J. Agric. Food Chem. 2007, 55, 4289-4298. [CrossRef]

11. Rusinek, R.; Siger, A.; Gawrysiak-Witulska, M.; Rokozik, E.; Malaga-Toboła, U.; Gancarz, M. Application of an electronic nose for determination of pre-pressing treatment of rapeseed based on the analysis of volatile compounds contained in pressed oil.pdf. Int. J. Food Sci. Technol. 2020, 55, 2161-2170. [CrossRef]

12. Ghasemi-Varnamkhasti, M.; Mohtasebi, S.S.; Siadat, M.; Balasubramanian, S. Meat Quality Assessment by Electronic Nose (Machine Olfaction Technology). Sensors 2009, 9, 6058-6083. [CrossRef] [PubMed]

13. Knobloch, H.; Turner, C.; Spooner, A.; Chambers, M. Methodological variation in headspace analysis of liquid samples using electronic nose. Sens. Actuators B Chem. 2009, 139, 353-360. [CrossRef]

14. Cellini, A.; Blasioli, S.; Biondi, E.; Bertaccini, A.; Braschi, I. Francesco Spinelli Potential Applications and Limitations of Electronic Nose Devices for Plant Disease Diagnosis. Sensors 2017, 17, 2596. [CrossRef] [PubMed]

15. Wilson, A.D. Recent progress in the design and clinical development of electronic-nose technologies. Nanobiosens. Dis. Diagn. 2016, 5. [CrossRef]

16. Saktiawati, A.M.I.; Stienstra, Y.; Subronto, Y.W.; Rintiswati, N.; Gerritsen, J.-W.; Oord, H.; Akkerman, O.W.; van der Werf, T.S. Sensitivity and specificity of an electronic nose in diagnosing pulmonary tuberculosis among patients with suspected tuberculosis. PLoS ONE 2019, 14, e0217963. [CrossRef] [PubMed]

17. Deng, Y.; Sun, J.; Jin, H.; Khatib, M.; Li, X.; Wei, Z.; Wang, F.; Horev, Y.D.; Wu, W.; Haick, H. Chemically Modified Polyaniline for the Detection of Volatile Biomarkers of Minimal Sensitivity to Humidity and Bending. Adv. Healthc. Mater. 2018, 7, 1800232. [CrossRef]

18. Kim, J.-H.; Mirzaei, A.; Kim, H.W.; Kim, H.J.; Quoc Vuong, P.; Kim, S.S. A Novel X-Ray Radiation Sensor Based on Networked SnO2 Nanowires. Appl. Sci. 2019, 9, 4878. [CrossRef]

19. Liu, H.; Zhu, W.; Han, Y.; Yang, Z.; Huang, Y. Single-Nanowire Fuse for Ionization Gas Detection. Sensors 2019, 19, 4358. [CrossRef]

20. Rudnitskaya, A. Calibration Update and Drift Correction for Electronic Noses and Tongues. Front. Chem. 2018, 6, 433. [CrossRef]

21. Liang, Z.; Tian, F.; Yang, S.; Zhang, C.; Sun, H.; Liu, T. Study on Interference Suppression Algorithms for Electronic Noses: A Review. Sensors 2018, 18, 1179. [CrossRef]

22. Tian, F.; Zhang, J.; Yang, S.; Zhao, Z.; Liang, Z.; Liu, Y.; Wang, D. Suppression of Strong Background Interference on E-Nose Sensors in an Open Country Environment. Sensors 2016, 16, 233. [CrossRef] [PubMed]

23. Sweelssen, J.; Blokland, H.; Rajamäki, T.; Boersma, A. Capacitive and Infrared Gas Sensors for the Assessment of the Methane Number of LNG Fuels. Sensors 2020, 20, 3345. [CrossRef] [PubMed]

24. Vargas-Rodriguez, E.; Guzman-Chavez, A.; Baeza-Serrato, R. Tailored Algorithm for Sensitivity Enhancement of Gas Concentration Sensors Based on Tunable Laser Absorption Spectroscopy. Sensors 2018, 18, 1808. [CrossRef] [PubMed]

25. Gancarz, M.; Nawrocka, A.; Rusinek, R. Identification of Volatile Organic Compounds and Their Concentrations Using a Novel Method Analysis of MOS Sensors Signal. J. Food Sci. 2019, 84, 2077-2085. [CrossRef]

26. Marek, G.; Dobrzański, B.; Oniszczuk, T.; Combrzyński, M.; Ćwikła, D.; Rusinek, R. Detection and Differentiation of Volatile Compound Profiles in Roasted Coffee Arabica Beans from Different Countries Using an Electronic Nose and GC-MS. Sensors 2020, 20, 2124. [CrossRef]

27. Lu, C.-J.; Zellers, E.T. A Dual-Adsorbent Preconcentrator for a Portable Indoor-VOC Microsensor System. Anal. Chem. 2001, 73, 3449-3457. [CrossRef]

28. Chae, M.-S.; Kim, J.; Yoo, Y.; Kang, J.; Lee, J.; Hwang, K. A Micro-Preconcentrator Combined Olfactory Sensing System with a Micromechanical Cantilever Sensor for Detecting 2,4-Dinitrotoluene Gas Vapor. Sensors 2015, 15, 18167-18177. [CrossRef] 
29. Thomas, C.M.; Schneider, J.F. Odor Concentration to Enhance Electronic Nose Performance. Process Anal. Chem. 2007, 10, 43-55.

30. Cáceres, J.M.; Durán, C.M.; Gualdron, O.E. Thermal Desorption System for Breath Samples Analysis from Colombian Patients with Gastric Cancer. Chem. Eng. Trans. 2018, 6, 427-432. [CrossRef]

31. Biondi, E.; Blasioli, S.; Galeone, A.; Spinelli, F.; Cellini, A.; Lucchese, C.; Braschi, I. Detection of potato brown rot and ring rot by electronic nose: From laboratory to real scale. Talanta 2014, 129, 422-430. [CrossRef]

32. Fujioka, K.; Shimizu, N.; Manome, Y.; Ikeda, K.; Yamamoto, K.; Tomizawa, Y. Discrimination Method of the Volatiles from Fresh Mushrooms by an Electronic Nose Using a Trapping System and Statistical Standardization to Reduce Sensor Value Variation. Sensors 2013, 13, 15532-15548. [CrossRef] [PubMed]

33. Cole, M.; Covington, J.A.; Gardner, J.W. Combined electronic nose and tongue for a flavour sensing system. Sens. Actuators B Chem. 2011, 156, 832-839. [CrossRef]

34. Muenchmeyer, W.; Walte, A.; Matz, G. Improving electronic noses using a trap and thermal desorption unit. Sens. Actuators B Chem. 2000, 69, 379-383. [CrossRef]

35. Camara, E.H.M.; Breuil, P.; Briand, D.; de Rooij, N.F.; Pijolat, C. A micro gas preconcentrator with improved performance for pollution monitoring and explosives detection. Anal. Chim. Acta 2011, 688, 175-182. [CrossRef] [PubMed]

36. McCartney, M.M.; Zrodnikov, Y.; Fung, A.G.; LeVasseur, M.K.; Pedersen, J.M.; Zamuruyev, K.O.; Aksenov, A.A.; Kenyon, N.J.; Davis, C.E. An Easy to Manufacture Micro Gas Preconcentrator for Chemical Sensing Applications. ACS Sens. 2017, 2, 1167-1174. [CrossRef] [PubMed]

37. James, F.; Breuil, P.; Pijolat, C.; Camara, M.; Briand, D.; Bart, A.; Cozic, R. Development of a MEMS Preconcentrator for Micro-gas Chromatography Analyses. Procedia Eng. 2014, 87, 500-503. [CrossRef]

38. Yeom, J. Micro-preconcentrator Technology for Portable Gas Chromatography System. In Encyclopedia of Nanotechnology; Bhushan, B., Ed.; Springer: Dordrecht, Netherlands, 2015; pp. 1-8. ISBN 978-94-007-6178-0.

39. Xu, X.; Tian, F.; Yang, S.; Li, Q.; Yan, J.; Machacek, J. A Solid Trap and Thermal Desorption System with Application to a Medical Electronic Nose. Sensors 2008, 8, 6885-6898. [CrossRef]

40. Bourlon, B.; Ho, B.-A.P.; Ricoul, F.; Chappuis, T.; Bellemin Comte, A.; Constantin, O.; Icard, B. Revisiting gas sampling and analysis with microtechnology: Feasability of low cost handheld gas chromatographs. In Proceedings of the 2016 IEEE Sensors, Orlando, FL, USA, 30 October-3 November 2016; pp. 1-3. [CrossRef]

41. Bourlon, B.; Ricoul, F.; Beghi, S.; Bellemin-Comte, A.; David, N.; Bordy, T.; Icard, B.; Salette, A.; Petitjean, M.; Barattin, R.; et al. Silicon Based Micro-Preconcentrators For Portable Gas Analysis Systems. In Proceedings of the 18th International Conference on Miniaturized Systems for Chemistry and Life Sciences, MicroTAS 2014, San Antonio, Texas, TX, USA, 26-30 October 2014; p. 3.

42. Brenet, S.; John-Herpin, A.; Gallat, F.-X.; Musnier, B.; Buhot, A.; Herrier, C.; Rousselle, T.; Livache, T.; Hou, Y. Highly-Selective Optoelectronic Nose Based on Surface Plasmon Resonance Imaging for Sensing Volatile Organic Compounds. Anal. Chem. 2018, 90, 9879-9887. [CrossRef]

43. Gaggiotti, S.; Hurot, C.; Weerakkody, J.S.; Mathey, R.; Buhot, A.; Mascini, M.; Hou, Y.; Compagnone, D. Development of an optoelectronic nose based on surface plasmon resonance imaging with peptide and hairpin DNA for sensing volatile organic compounds. Sens. Actuators B Chem. 2020, 303, 127188. [CrossRef]

44. Maho, P.; Herrier, C.; Livache, T.; Rolland, G.; Comon, P.; Barthelmé, S. Reliable chiral recognition with an optoelectronic nose. Biosens. Bioelectron. 2020, 159, 112183. [CrossRef]

45. Garbacz, M.; Malec, A.; Duda-Saternus, S.; Suchorab, Z.; Guz, Ł.; Łagód, G. Methods for Early Detection of Microbiological Infestation of Buildings Based on Gas Sensor Technologies. Chemosensors 2020, $8,7$. [CrossRef]

46. Aishima, T. Analysis of responses from a gas sensor array. Anal. Chim. Acta 1991, 243, 293-300. [CrossRef]

47. Schieweck, A.; Gunschera, J.; Varol, D.; Salthammer, T. Analytical procedure for the determination of very volatile organic compounds (C3-C6) in indoor air. Anal. Bioanal. Chem. 2018, 410, 3171-3183. [CrossRef] [PubMed]

(C) 2020 by the authors. Licensee MDPI, Basel, Switzerland. This article is an open access article distributed under the terms and conditions of the Creative Commons Attribution (CC BY) license (http://creativecommons.org/licenses/by/4.0/). 